\title{
Deep learning for computer-aided medical diagnosis
}

Published online: 29 April 2020

(C) Springer Science+Business Media, LLC, part of Springer Nature 2020

Multimedia Tools and Applications gratefully acknowledges the editorial work of the scholars listed below on the special issue entitled "Deep Learning for Computer-aided Medical Diagnosis" (SI 1119).

Of 68 papers submitted to this issue, 33 were eventually accepted after a stringent peer review process.

\section{Corresponding Guest Editor}

Yu-Dong Zhang

University of Leicester, UK

Email: yudongzhang@ieee.org; yz461@le.ac.uk

\section{Guest Editors \\ Zhengchao Dong}

Columbia University, USA

Email: zd2109@columbia.edu

\section{Carlo Cattani}

University of Tuscia, Italy

Email: cattani@unitus.it

Publisher's note Springer Nature remains neutral with regard to jurisdictional claims in published maps and institutional affiliations. 